\title{
In League? Destination Marketing Organisations and Football Clubs in the Virtual Space
}

\author{
Gerard Dunne \\ Technological University Dublin, gerard.dunne@tudublin.ie \\ David Proctor \\ Stenden University, david.proctor@stenden.com \\ Sheila Flanagan \\ Dundalk Institute of Technology
}

Follow this and additional works at: https://arrow.tudublin.ie/tfschhmtart

Part of the Advertising and Promotion Management Commons, Marketing Commons, Sports Management Commons, and the Tourism and Travel Commons

\section{Recommended Citation}

David Proctor, Gerard Dunne \& Sheila Flanagan (2018): In league? Destination marketing organisations and football clubs in the virtual space, Journal of Sport \& Tourism, DOI: 10.1080/14775085.2018.1523744

This Article is brought to you for free and open access by the School of Tourism \& Hospitality Management at ARROW@TU Dublin. It has been accepted for inclusion in Articles by an authorized administrator of ARROW@TU Dublin. For more information, please contact arrow.admin@tudublin.ie, aisling.coyne@tudublin.ie, gerard.connolly@tudublin.ie.

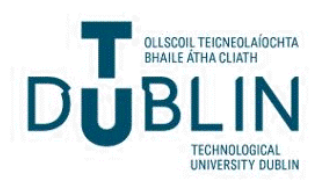




\section{In league? Destination marketing organisations and football clubs in the virtual space.}

David Proctor, Gerard Dunne and Sheila Flanagan

Logic dictates that Destination Marketing Organisations (DMOs), while representing many stakeholders, should leverage a location's most visible assets to enhance the attractiveness of the destination at any given opportunity. This study examines the manner and extent to which four major European football franchises are mentioned and promoted on the official digital marketing platforms of their respective cities; Amsterdam, Barcelona, Manchester and Munich. A tailor made content analysis tool is used to conduct a systematic investigation of the virtual platforms over which the DMOs of these cities exert a modicum of control. The content of these platforms is scrutinised from three perspectives; promotional, information dissemination or push towards purchase via external links. The four cities forming part of this study are home to some of the world's most iconic global sporting brands. The research uncovers a level of confusion or simple lack of know-how on the part of DMOs as to how these hugely popular clubs can or should be exploited in the digital space. It proffers solutions to this dilemma as in initiating cooperative marketing efforts between the respective organisations and exposes a contemporary field that necessitates further research.

Key words: destination marketing organisations; football clubs; online platforms; leveraging; city marketing.

\section{Introduction}

Destination Marketing Organisations (DMOs) operate in a very challenging environment. Frequently this comes about as the result of political machinations, the lack of stakeholder support or even the enormity of the task with which they are charged. In reality, however, the greatest obstacle placed in the path of the DMO is that of budgetary constraints (Zach, 2012). DMOs, the world over, are invariably under-staffed and under-financed yet they often exert an influence that belies such an apparent lack of resources (Hays, Page \& Buhalis, 2013). Finding the right mix, particularly when it comes to city marketing, can be a daunting task yet some locations possess unique attributes that they are either reluctant to capitalise on or are simply unsure of how to do so. 
This paper looks at the case of four cities where the opportunity to exploit a particular competitive advantage appears to exist. Amsterdam, Barcelona, Manchester and Munich enjoy considerable tourism trade. They are endowed with an extensive array of conventional tourism products yet each city is also home to what can be described as an entertainment brand whose reach far exceeds that of any DMO. Football clubs are often the visible manifestation of place and these cities, to greater or lesser degrees, are synonymous with the clubs of Ajax, FC Barcelona, Manchester United and Bayern Munich. In terms of branding some of these entities are instantly recognisable global behemoths.

Logic suggests that DMOs, whilst representing many stakeholders, should leverage a location's most visible assets to enhance the attractiveness of the destination at any given opportunity. This study investigates the manner in which each of these organisations engages with its respective (best known) football club in the digital space. The ubiquity of online platforms, their ease of use and opportunity for interaction with advocates of a destination, plus potential visitors, are essential weapons in the arsenal of DMOs. The current 'state-of-play' is examined from a logistical perspective while a content analysis tool is deployed to identify the messages conveyed via the multitude of virtual networks over which DMOs exercise a certain degree of control.

\section{Literature review}

Destination marketing is a highly competitive activity especially when related to urban tourism. Cities vie with one another in attracting sufficient numbers of visitors to develop, maintain, expand and ultimately sustain, over the long term, an industry that employs large numbers of people and plays a significant role within the local or national economy. According to Pike (2007) the entities charged with promoting localities, Destination Marketing Organisations (DMOs), can be traced back to 1864 when St. Moritz (Switzerland) established its own regional tourism agency. Over time and with the increasing realisation that a coordinated approach to destination promotion was beneficial, the number of DMOs has increased exponentially. It is estimated that by the turn of the last decade in excess of 10,000 such organisations were in existence (Pike, 2008).

Kavaratzis (2004) suggests that DMOs are the driving force behind the place marketing of a destination. He describes place marketing as being the strategic marketing of a nebulous intangible in contrast to conventional marketing which involves the promotion of much clearer and specific goods and services. Products have long been associated with places. Champagne and Scotch whiskey are clearly two such products with strong links to certain regions yet it could be argued that neither product, particularly in the 
case of Champagne, conjures up any real or specific connotation of place. Other products may be imbued with place characteristics. The example of the quintessential Swiss watch places the product firmly in the psyche with Swiss characteristics of reliability, attention to detail and expense. The ubiquitous Irish pub is similar in that it evokes images or sentiments specifically related to one country or place.

As DMOs attempt to create a brand image for a destination it is important to note that local communities are the primary stakeholders and their attitude towards place marketing ultimately dictates its effectiveness (Palmer, Konig-Lewis \& Jones, 2013). From a tourism perspective the local community act as ambassadors for the location, provide the services and products dispensed plus they create the essence of place which is integral to branding efforts (Kavaratzis \& Ashworth, 2008). Incorporating elements associated with a particular sports franchise or football club into the image of place may not garner community wide support, yet Sparvero and Chalip (2007) note the importance of professional sports teams in the creation of community value. Devine, Boyle and Boyd (2014) recognise the challenges faced by DMOs in incorporating sporting elements into the branding of destinations and bemoan the lack of 'joined-up thinking' in developing coherent sports tourism policy. They further posit that collaboration is a prerequisite for such efforts to be effective. Sports franchises, as commercial enterprises, jealously guard image rights adding yet another dimension into an already extremely complex mix (Nufer, 2016).

Place marketing initiatives touching on the domain of sport have often revolved around what can be termed mega-events. Such events including the Olympic games (both summer and winter) have been studied by a multitude of researchers including but not limited to Hagn \& Maennig (2009), Horne \& Manzenreiter (2004), Preuss (2004), Karadakis \& Kaplanidou (2010). Traditionally these iconic sporting tournaments witnessed fierce competition from cities and regions vying for the prestige of playing host. Conventional wisdom suggested that the net benefits of attracting such stand-out events outweighed the expense and inconvenience involved; both largely foisted on the shoulders of the local population and taxpayers. Undoubtedly accommodating such events heightens the public's awareness of a location for a particular moment in time but outside of some positive legacies in terms of urban regeneration, as observed in Barcelona (summer Olympics 1992) and Manchester (the Commonwealth games of 2002), the notion of inevitable net benefits accruing to a host city has been largely dispelled (Higham, 1999, Bason, Cook \& Anagnostopoulus, 2015). In contrast annual hallmark events, and more specifically the presence of a 'hallmark team' involved in regular season long competition, have been seen as a distinct asset in contributing to destination image whilst providing economic and other benefits within the local community (Allan, Dunlop \& Swales, 2007, Stevens, 2001). 
Few corporations on the planet have the brand recognition enjoyed by the world's major football clubs. Manchester United and FC. Barcelona are as recognisable to most people as Coca-Cola and Pepsi. Whereas the latter are not synonymous with a particular locality, save for their country of origin, the former are practically the visible representation of place on a global scale; in this case the cities of Manchester (England) and Barcelona (Spain). The emergence of these mega-brands is a significant cultural phenomenon and is down, in large part, to the increased media enhanced profile of the game and the commodification of sport into tangible elements which can be bought and sold (Bodet \& Chanavat, 2010). Not only have clubs been commoditised but players such as David Beckham or Cristiano Ronaldo have developed highly successful brands around their personas (Vincent, Hill \& Lee, 2009).

The on-field success of these football clubs is mirrored by their off-field business acumen translating itself into significant financial returns through the sales of tickets plus other merchandise and services. This has been adapted in more recent times with the aforementioned franchises each hosting extensive football themed museums showcasing the history of their organisations which appeal to visitors as well as locals. In the case of Manchester United, the club's museum welcomed over 300,000 people in 2013 (Bourne, 2013) and won the region's award for best large tourist attraction.

The sheer global notoriety of these sporting brands imbues them with a liminal quality transforming them by extension into sites of interest to visitors. A study conducted by the Sport Industry Research Centre of Sheffield Hallam University (2013) calculated that hotel occupancy rates rose by an average of $15 \%$ on days when Manchester United played at home and that the gross value added (GVA) of football to the Greater Manchester region was some $£ 330$ million during that same year. These figures are substantial and indicate the extent to which tourism can be enhanced to the benefit of all stakeholders. However it should also be noted that football, and indeed certain football clubs can also act as an impediment to inbound tourism particularly for non-sport tourists. Some clubs are loved and loathed in equal measure, as are players, their on/off the field antics, the excessive amounts of money involved and the spectre of hooliganism which still looms large over the sport (Weed, 2002, Pearson 2012).

\section{DMOs and the online space}

The advent of the internet and the rise of social networks have revolutionized the manner in which DMOs conduct their affairs ( $\mathrm{Li}$, Robinson \& Oriade, 2017). The convenience of the virtual world has also fundamentally changed how travellers access information, the way they plan for, manage and book trips, but perhaps most importantly, how they share information with others (Hays, Page \& Buhalis, 2013). Both the supply and demand sides of the tourism equation have witnessed a swift evolutionary process that continues to transform and define the future of destination marketing (Giannopoulus \& Mavragani, 
2011). This is a far cry from the days when DMOs felt compelled, as a matter of course, to claim their online space exclusively in the form of a proprietary website, often lacking in originality and usefulness (Woodside, Vicente \& Duque, 2011). As the importance of online communication became apparent DMOs adapted their portals to include blogs, forums and other tools but essentially the internet remained an instrument characterised by ‘one-to-many’ promotional messages (Sevin, 2013).

DMOs have branched out from proprietary websites to establishing a strong presence on social networks such as Facebook, Twitter, Instagram and Youtube (Alizadeh \& Isa, 2015). Many have also developed successful applications for smartphones and tablet computers. These platforms allow for inter-personal exchanges, sharing of information, reviews and establishing communities of advocates (or detractors) amongst others. They also permit cost effective target marketing to prospective customers who have displayed some level of interest in a product or service (Bruhn, Schoenmueller \& Schafer, 2012). Despite slow progress DMOs are gradually coming to terms with this new environment and are beginning to move away from utilizing these resources for purely promotional reasons. Commercial interests within destinations have been far quicker to exploit the currency of social media as a tool to engage with their audiences, encourage loyalty and effectively manage the customer relationship process. Football clubs, in particular, have been in the vanguard of this movement (Kuper, 2014).

That there are clear advantages and disadvantages associated with the use of sport in all its guises in promoting a destination is a given. The subject and issues involved have been the focus of significant research over the years (Kulczycki, 2005, Morgan \& Summers, 2005, Garrod \& Fyall, 2013, Gammelsaeter, 2017). This particular study does not revisit the arguments made by these authors but instead focuses specifically on the usage and leverage within the digital environment of iconic football brands by their respective DMOs. To this end a number of research alternatives were considered before ultimately deciding on, what was deemed to be, the most appropriate approach to take.

\section{Method}

This study is comprised of elements that are both exploratory and comparative in nature. Such a design is necessary as it allows several objects in the digital field to be explored and compared with a view to discerning similarities and differences (Paisey \& Paisey, 2009). The phenomenon being investigated lends itself to inquiries that necessitate pragmatic answers based on the logistics of 'what' and 'how' certain things are done while other more salient questions examine the meaning of such actions. 
A tailor made content analysis tool is used to conduct a systematic examination of the official virtual spaces of the DMOs of Amsterdam, Barcelona, Manchester and Munich. This focuses on identifying and analysing the approach employed by each DMO in relation to its city's most celebrated football club. The content of the platforms are investigated from three perspectives; promotional, information dissemination, and push towards purchase through external links. The popularity of each platform is also compared to those of each city's respective football club. In addition the rationale shaping the use of each platform is also considered.

Content analysis can be described as the approach taken for the analysis of texts, documents and audiovisual messages that quantifies such content in terms of predetermined categories in a systematic and replicable manner (Krippendorff, 2004). It is flexible in that it can be applied to a wide variety of media and generally aims at providing objective descriptions of these categories (Vitouladiti, 2014). When conducted correctly content analysis is a reliable and straightforward technique that is unobtrusive, inexpensive and scores high in regard to ease of replication.

\section{The case and application of the method}

The primary aim of this study is to investigate the degree to which city DMOs leverage the world renowned football clubs in their destinations as tourism assets through their online platforms. Purposeful sampling has been used since this particular case looks at a limited population of cities that attract significant numbers of visitors and are synonymous with globally recognisable football clubs. DMOs for the cities of Amsterdam, Barcelona, Manchester and Munich have been pre-selected. The major football clubs of these locations; Ajax, FC Barcelona, Manchester United and Bayern Munich have been chosen based on their global reach and fan base. They can also be considered significant tourist attractions in their respective cities as they provide regular sports events (matches) and all four offer stadia tours and museums. This study limits itself to a set number of units of analysis in respect of the online platforms used by DMOs. These platforms consist of the DMO proprietary website, its Facebook page, Twitter feed, YouTube account, and Instagram account. The content of each of these websites or digital platforms was analysed in the context of four research questions that will now be stated and explained. -

\section{RQ1. To what extend does each city DMO mention its main football club across its digital platforms?}

The analysis of the internet platforms used by each DMO involved scanning each site for any mentions or references to the city's football club. This involved noting the place and context where mentions 
occurred. In the case of the proprietary website the number of drilldowns (i.e. the number of clicks) needed to reach the first mention of the club was recorded.

\section{RQ2. What is the nature of the content on each DMO's internet platform and how can it be described?}

In the matter of how the online content can be described there is a clear demarcation between the target audience of each message and how it is perceived by such audiences. The internet is often used to convey information that can be labelled as 'one-to-many' or effectively mass communication where no response is sought from those receiving the message. Some messages may seek to engage with the audience thus allowing it to respond through the use of text and interact with the original author and/or others targeted with the message. A third classification is where the author solicits and actively encourages those receiving the message to respond with substantive content of their own that provokes further discussion.

In addition content can be categorised according to its purpose or intention. For this study three categories are used to indicate the purpose of the material. 1) Information dissemination; this relates to content that provides awareness of a product while refraining from specifically endorsing or actively encouraging its purchase. 2) Information that is promotional in nature. Promotional messages may seek to modify behaviour and thought or simply reinforce it. The principal role of these messages is that of persuasion. Here DMOs clearly convey a positive consumer oriented message that incorporates the football club as an attractive component of the destination's product mix. The research looked at the extent to which the messages were specifically promotional as distinct from simply providing awareness. 3) The third category relates to content that can be termed push to purchase via external links. In the context of this work 'push-to-purchase' messages are defined as content that unequivocally transport the potential consumer to external platforms that directly offer opportunities to buy a product or service offered by the football club or that are clearly linked to it.

Message content was also investigated according to the intensity of the information as it appears across the websites and digital platforms. Three additional categories relating to messages of high, medium or low intensity have been formulated to deal with the force or strength of the message communicated e.g. a website/platform containing an external link to another website directly selling merchandise or tickets would be coded as push-to-purchase of high intensity whereas a message merely providing times and dates of a club's fixtures would be coded as information dissemination of low intensity.

\section{RQ3. How does each DMO platform rate in terms of popularity when compared to those of the football} clubs? 
Tracking visitor likes, rankings and overall popularity across platforms is a useful exercise that may indicate to DMOs if a case needs to be made for better inclusion of the football clubs as genuine tourism products in areas of promotion and awareness. It is a summative exercise that consists of gathering numerical data from the specified social media platforms in addition to checking the standing of each DMO's proprietary website according to the well-respected Alexa organisation's ranking system.

RQ4. What recommendations can be made in terms of how DMO's can leverage the main football club in their respective city across their digital platforms?

All four cities examined in this study contain iconic football clubs that have global reach and popularity. However, the extent to which each of the cities' tourist boards utilise and leverage that popularity on their digital platforms is less than clear. It is necessary therefore to explore what can be done by DMOs in terms of harnessing the online potential that stems from each football club's fame and recognition.

Data analysis: Upon completing the data collection phase all relevant information was collated and analysed by the researchers. Once coded the data was re-checked and verified thus enabling accurate analysis. All categories and sub-categories were carefully reviewed in order to identify patterns, relations and inconsistencies. Each DMO and its related digital platforms were individually scrutinised before grouping the platforms across all locations to facilitate a comparative examination with commonalities and differences highlighted. The research questions and the study's rationale directed the analysis on all levels.

Reliability and validity: One of the principal reasons to conduct content analysis is to obtain objective information (Patton, 2002). The researchers meticulously developed the content analysis tool and took great care to ensure that it was consistently applied to the sample. One researcher performed the primary research and acted as a lone coder while all authors collaborated in developing the coding scheme. To verify the reliability of the tool it was applied twice, under similar conditions, to all platforms coded. The coder effectively re-coded each platform to corroborate whether the original data gathered was accurate and complete. Although no test for inter-rater reliability was conducted the coding scheme was discussed at length and externally audited by colleagues thus meeting the criteria in terms of credibility as suggested by Guba (1981). 


\section{Results}

Data was collected over a two day period covering March $9^{\text {th }}$ and $10^{\text {th }}, 2016$. Outside the gathering of basic numerical and ranking information the research strategy looked at identifying any incidence where virtual platforms administered by DMOs allude to the destination's primary football club in the digital space. Web pages falling within the same category were subject to identical search strategies across all destinations e.g. every Facebook page was examined in an identical manner regardless of the city. The following section looks at each city systematically with major findings highlighted.

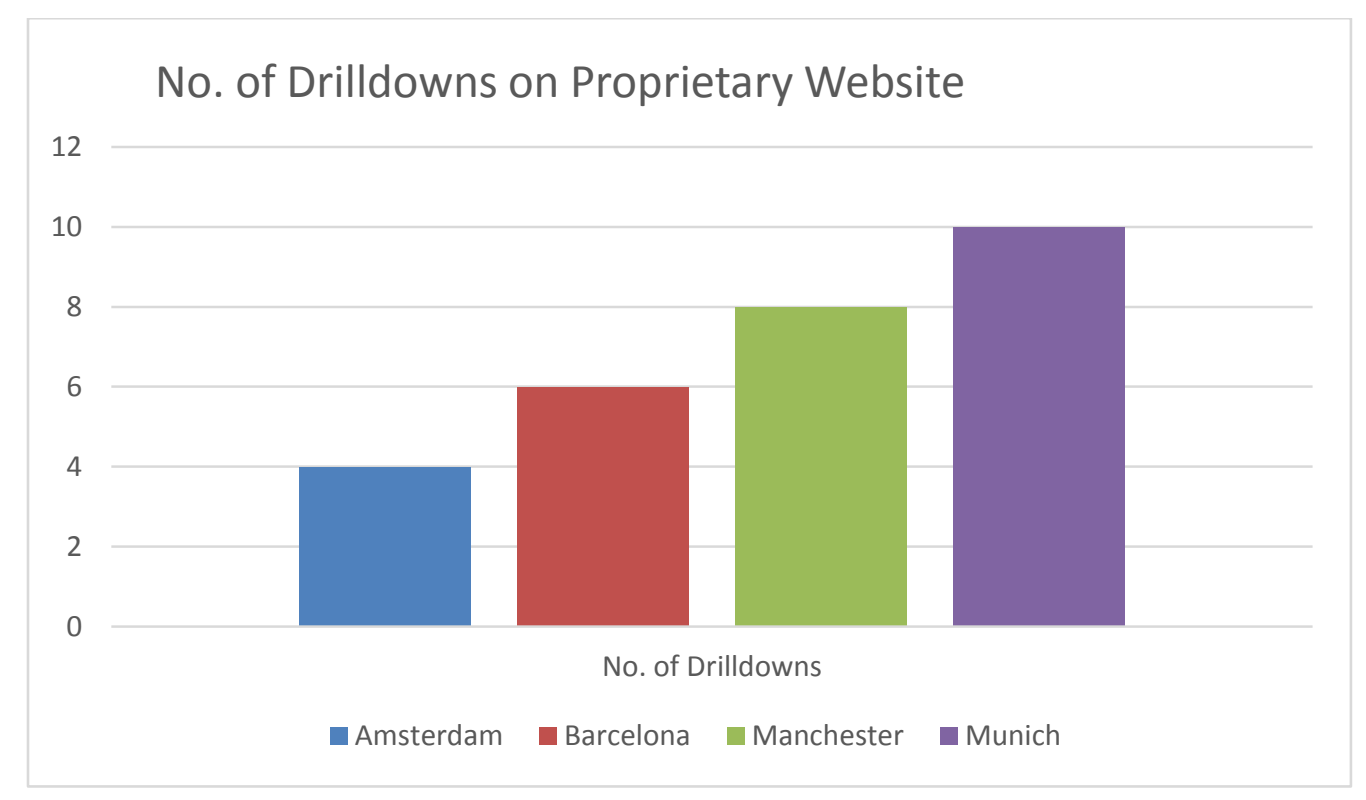

Figure 1. Shows drill down statistics for first reference of football club on DMO proprietary website 


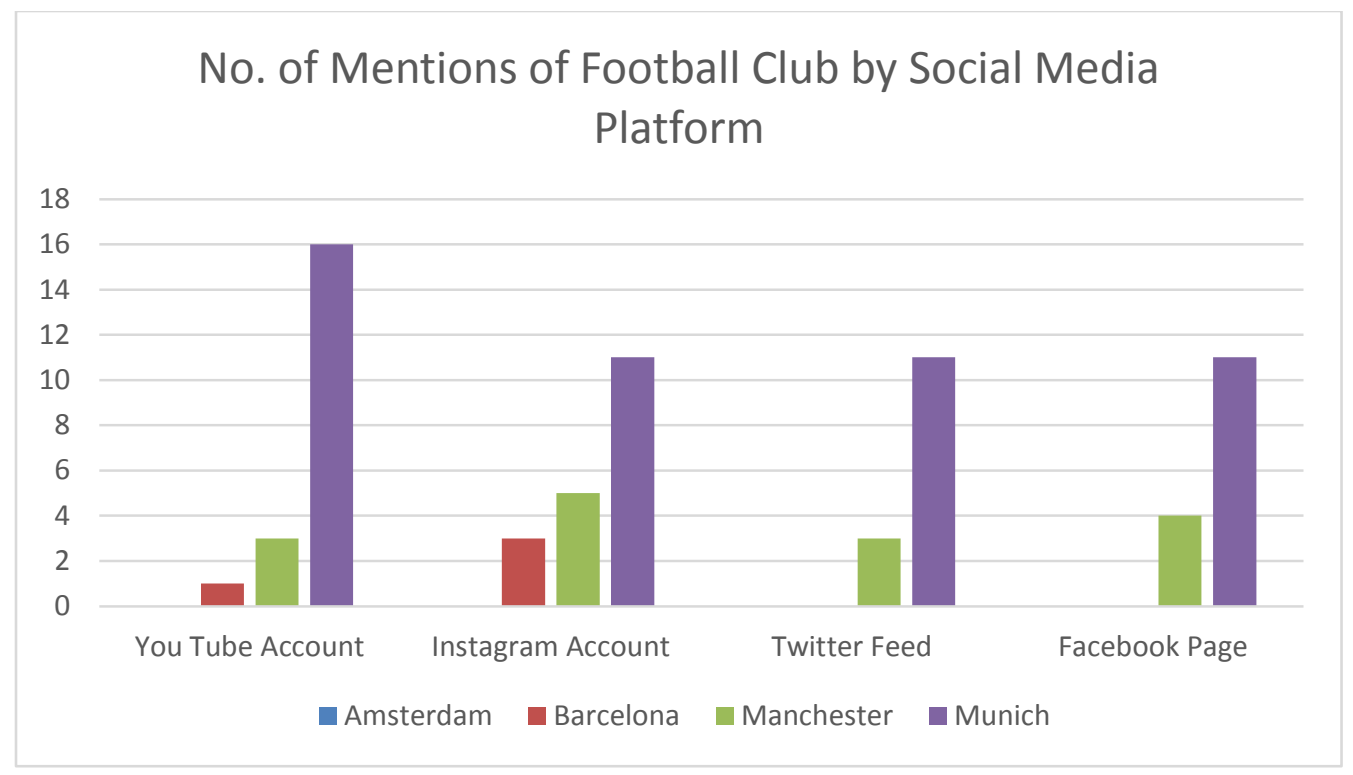

Figure 2: Number of mentions of the city's main football club on DMO's social media platforms

Manchester: The city is well represented across the entire digital spectrum. The DMO's proprietary website, VisitManchester.com, is ranked $294,626^{\text {th }}$ globally in terms of popularity according to Alexa Analytics (a subsidiary of Amazon.com that specialises in web intelligence). The DMO site's general content is delivered under the guise of mass communication with limited scope for audience interaction or user-generated content. In drilling down from VisitManchester.com's homepage, following the most obvious route, the city's football club is first directly mentioned two pages in. The message transmitted is promotional in nature and can be described as medium intensity according to the coding criteria. This in turn leads to another page where the tone of the message transmutes to that of 'push-to-purchase' of high intensity where an external link is offered which allows visitors opportunities to purchase football goods and services. Visitmanchester.com does not allow the user to directly buy football club related merchandise or tickets internally within its domain.

In relation to VisitManchester's social media sites it was found that the content across all its platforms was highly interactive and on the whole user generated responses were encouraged. However mention of Manchester United football club on these sites was quite sporadic. The Facebook page, as with those of the other cities, was scrutinised over a two month period. This resulted in four incidences where the football club was referred to via content that can be described as promotional of medium intensity. The football club was also mentioned 4 times over the same two month period on the DMO's Twitter feed which can also be described as promotional of medium intensity. VisitManchester's official Instagram 
account features two incidences of photographs related to the football club which can be categorised as information dissemination of low intensity while on YouTube two videos were present; one promotional but of low intensity, the other information dissemination of low intensity.

Munich: The city's proprietary website, Muenchen.de, is ranked $22,322^{\text {nd }}$ globally in terms of popularity (Alexa, 2016). The site's content is delivered under the guise of mass communication with no scope for audience interaction or user-generated content. In drilling down from Muenchen.de's homepage, following the most obvious route, the city's famous football club FC Bayern Munich is first directly mentioned two pages in. The material transmitted can be described as information dissemination of low intensity. Additional mentions of the football club were found further in, with a link to an external website offered to visitors four pages from the homepage. Muenchen.de does not allow the user to directly buy football club related merchandise and/or tickets within its domain.

Analysis of Munchen.de's social media platforms resulted in 33 instances where FC Bayern Munich is referred to. The messages conveyed are almost equally split between being promotional or information dissemination of generally medium intensity with no push-to-purchase intent. Interestingly the most common platform where the football club appeared was YouTube with 13 incidences. This was followed by Twitter and Facebook with 7 each and Instagram with 6 mentions.

Amsterdam: IAmsterdam.com is the city DMO's proprietary website that functions in a manner providing mass communications to users with little or no opportunity for audience interaction or user generated content. It is ranked as the $30,720^{\text {th }}$ most popular website globally by Alexa (2016). The search strategy followed the most obvious route in examining references to the Ajax football club of Amsterdam. From the homepage four drilldowns were necessary to uncover the first incidence referring to the football club. The message conveyed met the criteria for information dissemination of medium intensity that in turn led to another page featuring information dissemination of high intensity resulting in an external link to the football club. The domain does not offer users possibilities to purchase goods or services related to Ajax football club.

Remarkably, over the two month period analysed, there were no instances where Ajax FC was referred to on any of IAmsterdam.com's social media platforms.

Barcelona: Barcelonaturisme.com is the official site of the city's DMO. It has a ranking of 103,137 in global popularity according to Alexa (2016). In following the same research path as the other proprietary domains it was found that two drilldowns from the homepage were required to reveal the first instance where the city's iconic football club is referred to. The message can be categorised as one of information 
dissemination of low intensity that subsequently leads to a similarly categorised message of medium intensity. A further drilldown features a promotional message of high intensity but excludes a push-topurchase external link. In fact, Barcelonaturisme.com was the only DMO website (of the four researched) which offered users the possibility of directly purchasing goods and services linked to its city's famous football club within the proprietary environment.

Visit Barcelona is the social media incarnation of Barcelonaturisme (DMO). In drilling down through the same four platforms a total of four incidences are identified where FC Barcelona is referred to. One can be found on YouTube where the message is categorised as being of low intensity information dissemination and three on Instagram which relates to content of a promotional nature. Interestingly, no mention of FC Barcelona was found on either the DMO's Facebook page or Twitter account.

It is clear from the results that all destination marketing organisations are deeply committed online in terms of promoting their respective locations. Each organisation has spread its efforts over a significant number of platforms that are constantly evolving. The results highlight the level to which DMOs engage in utilising their respective football clubs as part of the bona fide tourism offer but they also underline the similarities and differences in how each DMO goes about trying to achieve this.

Table 1. Popularity of each DMO and football club social media platform on March $10^{\text {th }}$, 2016 as per figures visible on each portal.

\begin{tabular}{|l|c|c|c|c|c|c|c|c|}
\hline \multicolumn{7}{|c|}{ Social Media Popularity Table - DMO v Football Club } \\
\hline & $\begin{array}{l}\text { Amsterd } \\
\text { am DMO }\end{array}$ & Ajax Fc & $\begin{array}{c}\text { Barcelona } \\
\text { DMO }\end{array}$ & $\begin{array}{c}\text { FC } \\
\text { Barcelona }\end{array}$ & $\begin{array}{c}\text { Manchester } \\
\text { DMO }\end{array}$ & Man Utd & $\begin{array}{c}\text { Munich } \\
\text { DMO }\end{array}$ & $\begin{array}{c}\text { FC Bayern } \\
\text { Munich }\end{array}$ \\
\hline $\begin{array}{l}\text { FaceBk } \\
\text { Likes }\end{array}$ & 676047 & 2064332 & 80144 & 91051504 & 70407 & 68393071 & 488320 & 35323158 \\
\hline $\begin{array}{l}\text { Twitter } \\
\text { Followers }\end{array}$ & 174000 & 643000 & 9762 & 7180000 & 119000 & 7380000 & 72800 & 2650000 \\
\hline $\begin{array}{l}\text { Instagram } \\
\text { Followers }\end{array}$ & 4945 & 261000 & 28300 & 30200000 & 10100 & 9800000 & 34400 & 5900000 \\
\hline $\begin{array}{l}\text { Youtube } \\
\text { Sub. }\end{array}$ & 1692 & 110794 & 0 & 2196566 & 582 & 4160 & 1821 & 453896 \\
\hline
\end{tabular}




\section{Discussion}

Destination Marketing Organisations face a challenge when it comes to utilising, what are often globally recognised brands, as components of the tourism product. This study has looked at the inclination of these organisations to incorporate four world renowned football clubs into the information and promotion mix across four social media platforms and via each organisation's proprietary website. The stark conclusion drawn from the results is that significant gaps are evident in terms of exploiting these assets from a tourism or place marketing perspective. The activity uncovered for this study clearly identifies organisations that are more dynamic than others in the online environment.

Proprietary Websites: Each DMO in the cities of Manchester, Munich, Amsterdam and Barcelona controls its own visitor oriented website whose raison d'etre is to promote the respective location. All do so to varying degrees but it is interesting to note that these platforms, with the exception of VisitManchester.com, do not seek to engage the user or allow for user generated content. Given the present day propensity towards active engagement with the consumer this is somewhat surprising. While all proprietary websites investigated mention the local football club, only those of Manchester and Barcelona could be categorised as purveying content relating to the football clubs that push the prospective tourist towards purchase and hence initiating a visit (either to a game or a stadium visit). Out of the four DMO websites only that of Barcelona allows for direct purchase of match tickets within its domain while that of Manchester delivers the online user relatively quickly to portals that allow for purchases to be made. None of the proprietary websites use visuals of the football clubs on their homepages suggesting that they may not be deemed appropriate as representative images of the city for the wider audience.

According to website rankings furnished by the Alexa organisation it is clear that DMO websites lag seriously behind in terms of popularity when compared with their illustrious footballing partners. That the website of Visitmanchester.com finds itself in position 294,626 while that of ManUtd.com is within the top 10,000 most frequented websites worldwide suggest that the case for leverage is already evident. The incongruence of this relationship is further exposed in the realm of social media where distinctions become even starker. All the proprietary domains investigated feature links to a number of social media platforms created by each DMO. The results show their utilisation of these platforms to be quite variable and inconsistent.

Facebook: This was the social media platform of choice for all cities within this study. The Facebook pages of DMOs vary in popularity (likes) as do the levels of activity and updating of content. This was clearly observed during data collection. Significant differences emerged as to how the respective football 
clubs are included or promoted as part of a destination's tourism product. Iamsterdam's Facebook page was by far the most popular of those investigated yet no content related to the respective football club (Ajax) was observed over a two month period. Barcelona, similarly, eschewed coverage of its celebrated football club over the same period while the DMO's of Manchester and Munich posted occasional updates that were mostly promotional in the case of the former and information dissemination in terms of the latter. An interesting observation here is that the less visited cities such as Manchester and Munich were more inclined to utilise their sporting asset whereas cities that are world famous for other visitor attractions seemed less disposed to do so. That Barcelona, whose football club has 91 million Facebook likes compared to 80,144 for its Visit Barcelona page, makes no reference to the football club is puzzling since it is clearly a visitor attraction and suggests a possible missed opportunity in terms of how the asset can be exploited in a tourism context.

The results stemming from the investigation of Facebook are particularly interesting when the levels of popularity are compared (see Table 1). The disparity in the number of 'likes' between DMO sponsored pages and those of football clubs is startling and may indicate that cities are missing out on the opportunity of reaching a far wider audience.

Twitter: Although somewhat smaller in terms of reach Twitter results are directly related to those revealed on Facebook. Neither Amsterdam nor Barcelona make any effort on their Twitter platforms to utilise their respective football clubs over the timeframe scanned while Manchester and Munich appear to replicate their Facebook posts on Twitter despite the inherent differences of each platform. Such activity suggests organisations that are merely going through the motions and are far from certain of how to maximise the benefits in either environment. Twitter, with its 140 character limit and high potential for retweet or sharing of content, seems to be perceived as a bit player for the DMOs. However, it is still an important mode of communication for the football clubs as reflected in the significant numbers of followers they have achieved. As commercial entities it becomes increasingly apparent that football clubs have a clearer vision when it comes to engagement in the world of social media and networks.

Instagram: The photographic and video sharing phenomenon that is Instagram is potentially the ideal showcase for DMOs to display their locations to the world. Coupled with the use of hashtags Instagram lends itself to wide exposure and is used extensively by football clubs as in the case of FC Barcelona with over 30 million Instagram followers. Although all DMOs included in this study are present on the platform, their level of activity and number of followers vary immensely. Amsterdam generally fares quite poorly and is the only city that does not incorporate any subject relating to its football club (Ajax) within its content. Munich on the other hand is the most active city on Instagram both in terms of the 
number of posts (655) and the amount attributed to FC Bayern Munich. Instagram is a relatively late comer to the field of social media having debuted in 2010 before being acquired by Facebook. Evidently DMOs are still coming to terms with yet another communication channel but the findings here indicate another medium where the DMO/football club relationship is less than symbiotic.

YouTube: Alexa's web intelligence ranks YouTube as the third most visited website on the planet. DMOs are present on this platform but once again appear apprehensive or unsure as to how they might best communicate with the wider world via a format, when effectively exploited, permits high impact and persuasive audio-visuals. The four DMOs barely scrape the surface in leveraging the notoriety of their respective football clubs with only Munich employing this channel to any extent, through the posting of regular updates and content relating to FC Bayern Munich. YouTube poses particular challenges for DMOs since the content on their pages is expected to be of high quality thus necessitating the need for professional input. The cost of such assistance may be prohibitive for organisations that often face budgetary constraints and are constantly weighing up fiscal priorities.

\section{The case for leverage}

In analysing the data only Munich's DMO stands out as an organisation that appears to appreciate the tourism potential that its preeminent football club offers the city. Overall the results show relatively few incidences where any of the DMOs make reference to the football clubs in their respective cities. In the case of Amsterdam there was no mention whatsoever of Ajax FC on its social media platforms. This may relate to the fact that Ajax is a club that is least associated with the city in terms of its name and is also the least popular, on a global scale, of the football clubs within the study. Moreover, the visitor's image of the city of Amsterdam does not readily conjure up images of football or Ajax despite the celebrated nature of the club. Barcelona, on the other hand, is a city that is synonymous with football yet even here it appears that the city's DMO ignores what is a worldwide brand with a very positive image. Barcelona has a myriad of attractions that it can incorporate into its tourism offer but the relative absence of FC Barcelona from the DMO's social media output poses some serious questions as to whether the organisation is fully leveraging one of its city's premier tourism assets. In relation to Manchester the results indicate some efforts being made to incorporate the iconic Manchester United brand into its online marketing efforts but like the other cities it also seems unsure as to how to utilise the club in terms of presenting the city's tourism offer to the public. Manchester, of course, is also home to Manchester City FC, a club that has quickly gained in worldwide appeal following its acquisition by a wealthy United Arab Emirates based conglomerate. Manchester City has invested significant resources in turning around the fortunes of a team that has won the league title twice in the past four years and looks to attract star players with global 
reputations. City also lead the way in the use of innovative online and virtual reality technology in enhancing the visibility of its brand (Sammonds, 2017). The DMO, as a non-partisan entity, cannot be seen to favour one club over another or may risk alienating certain potential visitors due to the tribal like rivalry associated with the sport. Barcelona and Munich face a similar if less pronounced challenge when one considers the stature of their respective 'second' clubs i.e. Espanyol and 1860 Munich.

In gathering the data one particularly unexpected observation was made. DMOs almost universally failed to encourage audience participation or promote user-generated content. It was surprising and certainly unanticipated to discover that the manner of engagement of DMOs, particularly in the arena of social media, appears at odds with current marketing practice. Moreover one could speculate that the inclusion of content relating to highly recognisable football clubs within DMO administered social networking platforms would pay immediate dividends in terms of increasing popularity, and creating opportunities for meaningful engagement. DMOs, on the whole, appear either reluctant or indifferent when it comes to effectively incorporating football clubs into the image they wish to portray of their destinations in the virtual space.

\section{Limitations}

The study is restricted to four cities and is based on specific variables. Although the data collected points to a certain reality it is possible that if conducted at a different period of time, for example when seasonal competitions climax, the results might vary somewhat. The number of websites used was also restricted to a limited number of platforms, five in all, excluding some sites attracting significant traffic and user content. The research looked at websites presented in a number of different languages; primarily English but also in German and Spanish. Despite cross-checking for meaning with proficient German and Spanish speakers it is possible that some data was missed. Lastly, the method used; content analysis, limits the inferences that can be made based on the data collected. It is a purely descriptive method but may not reveal the underlying motives for an observed pattern.

\section{Practical recommendations}

The internet is an interactive space and it is incumbent upon DMOs to engage actively with their audience through dialogue and the promotion of user generated content that should provoke discussion and interest. These organisations need look no further than the football clubs in their respective cities for examples of best practice in this domain. In doing so DMOs should seek to stimulate cooperative marketing initiatives and co-opt the football clubs as partners in a mutually beneficial exchange (Zach, 2012). At the very least, 
attempts should be made to 'piggyback' on the popularity of these global brands thus increasing each city's exposure to a much wider audience. In the worst-case scenario this audience falls within a very specific target market that is nonetheless substantial and potentially capable of benefitting a variety of tourism stakeholders within the locality via increased patronage.

With the exception of Amsterdam all of the cities researched are home to more than one professional football club. Each destination marketing organisation faces particular challenges in this area and cannot be seen to be partisan in any way. It is suggested, in such cases, to jointly promote clubs as part of a tourism related football product that generates broader appeal. In one of these destinations (Manchester) the potential for such an initiative seems compelling especially considering the city is also home to the country's National Football Museum and both major sporting franchises, particularly Manchester City, are at the forefront in the use of web-based technology to promote brand awareness (Connelly, 2017). For destinations lacking in conventional tourism 'charm' and appeal this presents a serious opportunity for effective leverage.

The study highlights a lack of clear strategy when it comes to utilising these assets in the digital space. Each DMO should work on formulating an effective policy that actively incorporates these brands (and related others) in a manner that is beneficial to the growth of tourism in general. Such a policy should be consistent in its application and, where possible, be implemented with the explicit cooperation of the football clubs whose resources and reach are significantly greater than those of DMOs.

\section{Research recommendations}

This study opens up significant opportunities for further academic research. It can be expanded to other cities sharing similar characteristics or may focus on cities with less visible tourism attributes but who are home to football clubs of some repute e.g. the case of Leicester in the UK which is attracting worldwide media attention due to the recent unexpected success of its local team (Holmes, 2016). A comprehensive study encompassing all major online and mobile platforms would also provide a more complete picture of the issues at hand and give policy makers clearer indications of how to effectively leverage these assets in a wider context. It would also be of some interest to extend the data collection period in order to gauge whether issues relating to actual team performance, thus potentially causal events, result in more effective opportunities for leverage and development of flexible promotional strategies. In the same vein, researchers may look at destinations with other highly visible attractions and investigate them in a similar manner. 


\section{References}

Alexa Website Rankings (2016). In Alexa. Retrieved from: www.alexa.com

Alizadeh, A., \& Isa, R.M. (2015). The use of social media in destination marketing: An exploratory study. Tourism, 63(2), 175-192.

Allan, G., Dunlop, S. and Swales, K. (2007). The Economic Impact of Regular Season Sporting Competitions: The Glasgow Old Firm Football Spectators as Sports Tourists. Journal of Sport and Tourism, Vol. 12 No. 2, pp. 63-97

Bason, T., Cook, D., \& Anagnostopulus, C. (2015). Legacy in major sporting events: empirical insights from the 2010 FIFA World Cup in South Africa. Sports Management International Journal, 11(1), 44-61

Bodet, G., \& Chanavat, N. (2010). Building global football brand equity: Lessons from the Chinese market. Asia Pacific Journal of Marketing and Logistics, 22(1), 55-66.

Bourne, D. (2013, 7 November). Ouch! United cut City down to size at Manchester Tourism awards. Manchester Evening News. Retrieved from: http://www.manchestereveningnews.co.uk/sport/football/football-news/manchester-united-cutmanchester-city-6281238 
Bruhn, M., Schoenmueller, V., \& Schäfer, D.B. (2012). Are social media replacing traditional media in terms of brand equity creation? Management Research Review, 35(9), 770-790.

Connelly, T. (2017). Manchester City get smart with data to create personalised fan experience platform. Retrieved from: http://www.thedrum.com/news/2017/08/07/manchester-city-get-smart-with-data-createpersonalised-fan-experience-platform

Devine, A., Boyle, E. and Boyd, S. (2009). Towards a theory of collaborative advantage for the sports tourism policy arena. International Journal of Public Sector Management, Vol. 24 No. 1, pp. 23-41.

Gammelsaeter, H. (2017). Media visibility and place reputation: does sport make a difference? Journal of Place Management and Development, 10(3), 288-298.

Garrod, B., \& Fyall, F. (Eds.). (2013). Contemporary Cases in Sport. Oxford, England: Goodfellow.

Giannopoulus, A., \& Mavragani, E.P. (2011). Travelling through the web: A first step toward a comparative analysis of European national tourism websites. Journal of Hospitality Marketing \& Mangement, 20, 718-739.

Guba, E.G. (1981). Criteria for assessing the trustworthiness of naturalistic inquiries. Educational Communication and Technology Journal, 29, 75-91.

Hagn, F., \& Maennig, W. (2009). Large sport events and unemployment: the case of the 2006 soccer World Cup in Germany. Applied Economics, 41(25), 3295-3302. doi:10.1080/00036840701604545

Hays, S., Page, S., \& Buhalis, D. (2013). Social media as a destination marketing tool: its use by national tourism organisations. Current Issues in Tourism, 16(3), 211-239.

Higham, J. (1999). Commentary - Sport as an Avenue of Tourism Development: An Analysis of the Positive and Negative Impacts of Sport Tourism. Current Issues in Tourism, 2(1), 82-90.

Holmes, O. (2016, February 13). Leicester City's premier league miracle rocks the streets of Bangkok. The Guardian. . Retrieved from: http:theguardian.com/football/2016/feb/13/leciester-city-thailandfootball

Horne, J. D., \& Manzenreiter, W. (2016). Accounting for Mega-Events. International Review for theSociology of Sport, 39(2), 187-203. doi:10.1177/1012690204043462 
Karadakis, K., Kaplanidou, K., \& Karlis, G. (2010). Event leveraging of mega sport events: A SWOT analysis approach. International Journal of Event and Festival Management, 1(3), 170-185. doi:10.1108/17852951011077998

Kavaratzis, M., \& Ashworth, G. (2008). Place marketing: how did we get here and where are we going. Journal of Place Management and Development, 1(2), 150-65.

Kavaratzis, M. (2004). From city marketing to city branding: Towards a theoretical framework for developing city brands. Place Branding, 1(1), 58-73.

Krippendorff, K. (2004). Content analysis: An introduction to its methodology. Thousand Oaks, California: Sage Publications.

Kulczycki, C. (2016). Book Review: Sport Tourism Development. Journal of Travel Research, 43(3), 319-320. doi:10.1177/0047287504272037

Kuper, S. (2014, November 21). Football and social media. Financial Times. Retrieved from www.ft.com/s/2/7593cd8c-7401-11e4-bc6a-0014feabdc0.html\#axzz46ml1pzx7

Li, S.C.H,, Robinson, P., \& Oriade, A. (2017). Destination marketing: The use of technology since the millennium. Journal of Destination Marketing and Management, 6(2), 95-102.

Morgan, M.J.J., \& Summers, J. (2005). Sports Marketing. Victoria, Australia: Thomson.

Nufer, G. (2016). Ambush marketing in sports: an attack on sponsorship or innovative marketing? Sports, Business and Management: An International Journal, 6(4), 476-495.

Paisey, C. \& Paisey, N.J. (2009). Comparative research: An opportunity for accounting researchers to learn from other professions. Journal of Accounting \& Organizational Change, 6(2), 180-199.

Palmer, A., Konig-Lewis, N., \& Jones, L. (2013). The effects of residents' social identity and involvement on their advocacy of incoming tourism. Tourism Management, 38, 142-151.

Patton, M.Q. (2002). Qualitative Research and Evaluation Methods. Thousand Oaks, CA: Sage.

Pearson, G. (2012). An ethnography of English football fans, Manchester University press, Manchester.

Pike, S. (2008). Destination marketing. Burlington, VA: Butterworth-Heinemann.

Pike, S. (2007). Destination marketing organisations. New York, NY: Rutledge 
Preuss, H. (2004). The economics of staging the olympics: Acomparison of the games, 1972-2008. Cheltenham, UK: Edward Elgar Publishing.

Sammonds, C. (2017). Manchester City: Football's leading light in brand development. Retrieved from: https://channels.theinnovationenterprise.com/articles/manchester-city-football-s-guiding-light-in-branddevelopment

Sevin, E. (2013). Places going viral: Twitter usage patterns in destination marketing and place branding. Journal of Place Management and Development, 6(3), 227-239.

Sparvero, E., \& Chalip, L. (2007). Professional teams as leverageable assets: Strategic creation of community value. Sport Management Review, 10, 1-30.

Sport Industry Research Centre Sheffield Hallam University (2013). Analysing the value of football to Greater Manchester. Retrieved from http://neweconomymanchester.com/.../2416-280613-TechnicalReport-pdf

Stevens, T. (2001) 'Stadia and tourism related facilities,' Travel and Tourism Analyst, 2, 59-73.

Vincent, J., Hill, J.S., \& Lee, J.W. (2009). The multiple brand personalities of David Beckham: a case study of the Beckham brand. Sport Marketing Quarterly, 18(3).

Vitouladiti, O. (2014). Content analysis as a research tool for marketing management and development strategies in tourism. Procedia Economics and Finance, 9, 278-287.

Weed, M.E. (2002). Football hooligans as undesirable sports tourists: some meta-analytical speculations. In S. Gammon \& J. Kurtzman (Eds.), Sports Tourism: Principles and Practice. Eastbourne: Lesiure Studies Association.

Woodside, A.G., Vicente, R.M., \& Duque, M. (2011). Tourism's destination dominance and marketing website usefulness. International Journal of Contemporary Hospitality Management, 23(4), 552-564.

Zach, F. (2012). Partners and innovation in American destination management organizations, Journal of Travel Research, Vol. 51 No. 4, pp. 412-425. 